\title{
Moral Perception Beyond Supervenience: Iris Murdoch's Radical Perspective
}

\author{
Silvia Panizza ${ }^{1}$ (i) \\ Published online: 1 July 2019 \\ (c) The Author(s) 2019
}

\section{Introduction}

My aim in this paper is to flesh out Iris Murdoch's idea of moral perception and to put it in conversation with contemporary debates. The reason for doing so is that Murdoch proposes a radical account of moral perception which is not fully accounted for in recent discussions in analytic philosophy. The difficulties about moral perception depend on an assumption that true perception takes as its object a reality that is a) physical and b) non-moral. ${ }^{1}$ Defending some form of moral perception has generally consisted in explaining how moral properties are linked to such perceptual content proper. This has mainly been done by appealing to implicit principles or to moral concepts that function as bridges between phenomenal content and the real object of perception; these are not, however, defenses of moral perception per se, but rather explanations of the phenomenology of it. ${ }^{2}$ Or it has been done by establishing a closer link between the moral and the non-moral, through appeal to supervenience. ${ }^{3}$

Murdoch's account, on the other hand, depends on a metaphysics which questions the very distinction between the moral and the non-moral, and thus supports the possibility of direct perception of moral properties without the need for either

\footnotetext{
1 See David Faraci, "A Hard Look at Moral Perception,” Philosophical Studies 172:8 (2015): 20552072; Andrew Cullison, "Moral Perception," European Journal of Philosophy 18:2 (2010): 159-75; Robert Audi, Moral Perception (Princeton: Princeton University Press, 2013); Micheal Watkins and Kelly Dean Jolley, "Pollyanna Realism: Moral Perception and Moral Properties," Australasian Journal of Philosophy 80:1 (2002): 75-85; Pekka Väyrynen, "Doubts about Moral Perception,” in A. Bergqvist and R. Cowan (eds.) Evaluative Perception (Oxford: Oxford University Press, 2018).

2 See Gilbert Harman, The Nature of Morality: An Introduction to Ethics (Oxford: Oxford University Press, USA, 1977); Faraci, op. cit.; Väyrynen, op. cit.

3 See Timothy Chappell, "Moral Perception," Philosophy 83:4 (2008): 421-37; A.E. Denham, "Envisioning the Good: Iris Murdoch's Moral Psychology," Modern Fiction Studies 47:3 (2001): 602-629; Margaret Holland, "Touching the Weights: Moral Perception and Attention," International Philosophical Quarterly 38:3 (1998): 299-312.
}

Silvia Panizza

S.Panizza@uea.ac.uk

$1 \quad$ Norwich Research Park, University of East Anglia, Norwich NR4 7TJ, UK 
implicit bridges or supervenience - both of which rest on the recognition of an ontological gap between the moral and the non-moral. If direct moral perception is possible, we then have a different and more straightforward method of accounting for moral knowledge. However, a defense of moral perception does not need to claim either that a) all moral knowledge is acquired by perception, or that b) moral perception is always correct. It is sufficient to show that it is possible to acquire moral knowledge through direct perception, without it being exhaustive or always successful. This involves, crucially, the possibility of evaluating the correctness of perception. In the course of this discussion, I will be using "moral perception" as a success term, to indicate the perception of something which is there to be perceived. ${ }^{4}$

\section{Moral Perception in Iris Murdoch}

Despite arguing for moral perception at various points in her work, Murdoch only offers one sustained example of what she means by it, through the famous story of $\mathrm{M}$ and $\mathrm{D}$, where little detail is provided as to how perception occurs. Here is a summary of the story (with apologies to the reader who is excessively familiar with it), introduced in The Sovereignty of Good: $\mathrm{M}$ is a mother in law who has always judged her daughter in law D harshly, finding her (in Murdoch's words) "vulgar" and "juvenile;" then, with the passing of time, she starts questioning her view of $D$, realizing that she may have been biased or blinded by self-concern, and as a result she comes to have a very different view of her daughter in law, whom she now describes as "refreshingly simple."

Murdoch uses this story primarily in order to show how moral change can be inner change, by which she means involving no action at all, in opposition to the behaviorist model that was prevalent at the time she was writing. What is characteristic of this change, presented as an example (if not a paradigm) of moral progress, is that it occurs through a process that Murdoch calls "looking again" and is said to result in a more accurate vision of D: "When $\mathrm{M}$ is just and loving," Murdoch writes, "she sees D as she really is."

Several questions arise from this story. For our purposes, the relevant ones are: Firstly, is it really possible to say that M's perception of D is what has changed, or is the talk of vision merely metaphorical? Secondly, the story involves the claim that M's change is a change towards greater accuracy, implying that there is a fact of the matter about whether D is juvenile or refreshingly simple. How is this implication explained?

\footnotetext{
4 It is controversial whether Murdoch uses the phrase in the same way. Perception-related words like "seeing," "looking," "attention," are sometimes used as success-words, sometimes neutrally. For a full discussion of this question see Blum (Note viii).

5 Iris Murdoch, The Sovereignty of Good (London: Routledge and Kegan Paul, 1970).

6 Ibid., p. 37.
} 


\section{Two Meanings of Moral Perception}

A first distinction to be made concerns the meaning of "moral perception." Moral perception can refer to two different phenomena: first, it can be the idea that there is a morally relevant reality which can be revealed by perception; second, it can refer to the notion that one's perceptions are expressive of one's moral qualities and therefore correct perception depends on a morally good quality of consciousness, on virtuous attitudes and states of mind. ${ }^{7}$ It has been suggested by S.W. Clifton that this second way is how Murdoch understands moral perception; the ability to perceive correctly or clearly, he argues, is inherently valuable, being a "moral achievement" whatever its object. ${ }^{8}$

While this interpretation certainly captures one aspect of moral perception as construed by Murdoch, it also obscures the real reason for evaluating particular perceptive states. Drawing on Simone Weil, ${ }^{9}$ Murdoch calls the state of receptivity leading to successful moral perception "attention." 10 Attention can be considered a virtue, and that is why, as Clifton argues, attention is good in itself, because it is part of good character and involves other virtues like selflessness and love and justice. ${ }^{11}$ However, the moral importance of attention, or the virtuous aspect of attention, do not merely depend on making sure we are in a virtuous state involving clarity and honesty, but rather on making sure that we are seeing what is really there, not for our own sake, but for the sake of whatever it is that we are seeing - including the ability to focus on what is more important. The first and foremost reason for paying attention, in other words, is that the object, somehow, matters. As Murdoch stresses: "the direction of attention is outward, away from self."12

These points emerge, for instance, in Murdoch's comments on the Zen practice of meditation. Seeing stones and insects lovingly, justly and accurately is an exercise of virtue and, as such, it is a good thing to do. But part of its value depends, on the one hand, on the value of truth and reality, and on the other, on the fact that meditation is good training for seeing clearly other things that matter: after the practice, one needs

\footnotetext{
7 This distinction is drawn by Scott W. Clifton, "Murdochian Moral Perception," The Journal of Value Inquiry, 47 (2013): 207-220. It should be noted that the formulation "morally relevant reality" is neutral as to the existence of a moral reality, and also as to whether moral properties are perceived or inferred.

8 See Clifton, op. cit. and Lawrence Blum, "Visual Metaphors in Murdoch's Moral Philosophy," in J. Broackes (ed.), Iris Murdoch, Philosopher (Oxford: Oxford University Press, 2012), pp. 307-324.

9 See Sabina Lovibond, Iris Murdoch, Gender and Philosophy (London and New York: Routledge, 2011), p. 28-46; and Kate Larson, Everything Important is to do with Passion': Iris Murdoch's Concept of Love and its Platonic Origin (Uppsala: Universitetsbiblioteket, 2009).

${ }^{10}$ In The Sovereignty of Good (Note v, p. 34), Murdoch acknowledges the borrowing from Weil and refers to her thought at various places in her own work, although she never discusses at any length the extent to which she is indebted to Weil. Nonetheless, it is clear that Weil's concept of attention, developed in the context of mysticism and religious metaphysics, had a tremendous influence on Murdoch, who secularized it and inserted it within her own Platonist metaphysics. For a discussion of Weil's influence on Murdoch, see Lovibond and Larson (Note ix).

11 See Micheal Brady, "Virtue, Emotion, and Attention," in A. T. Marsoobian et al (eds.) Virtue and Vice, Moral and Epistemic (Malden: Wiley-Blackwell, 2011) and Nicolas Bommarito, "Modesty as a Virtue of Attention," The Philosophical Review 122-1 (2013): 93-117.

12 Murdoch 1970, op. cit., p. 66.
} 
to return to the world. ${ }^{13}$ The importance of observing stones and insects lovingly, Murdoch suggests, lies partly in its ability to train oneself to thus see other people, animals, and situations. ${ }^{14}$ It seems like an inversion of priority to claim, instead, that "what makes attention ... a moral achievement is not found in the specific cases in which an agent is able to see the suffering of others, but in all cases in which the agent sees the world aright as a result of the suppression of self'."15 Adopting this view would, besides obscuring the reasons why the virtues involved in attention are considered to be virtues, shift the focus of attention onto the subject, at the expense of the reality outside the subject, which is the proper object of attention.

Murdoch, in fact, combines the two senses of "moral perception" - the moral quality of the perceiving mind and the moral quality of the perceived reality - in a way that makes them indivisible. Let us see how.

\section{When Moral Perception Goes Wrong}

Since Murdoch's own example of moral perception has been criticized for being too "domestic" or private, and distant from pressing moral concerns, let us take two other examples where such concerns are unquestionably clear.

In April 2015, The Sun columnist Katie Hopkins published a piece in response to the sinking of a refugees' vessel off the Libyan coast resulting in over 400 deaths. The article represents a view that is still present in certain sections of public discourse. Under the headline "Rescue boats? I'd use gunships to stop migrants," Hopkins wrote:

No, I don't care. Show me pictures of coffins, show me bodies floating in water, play violins and show me skinny people looking sad. I still don't care ... These migrants are like cockroaches ... Drilling a few holes in the bottom of anything suspiciously resembling a boat would be a good idea, too. ${ }^{16}$

This contemporary example can be put side by side with a parable, used by Simone Weil to illustrate how attention and moral perception work: the parable of the Good Samaritan. ${ }^{17}$ While the Levite and the priest walk past with only a glance, the Samaritan stops to help the injured man by the side of the road (Luke 10:29-37).

Both of these are cases where something seems to go wrong in some of the participants' moral responses. Let us examine the possibility that in both, instead of moral progress by perception, as in the story of $\mathrm{M}$ and $\mathrm{D}$, we have what Murdoch may describe as moral failure. What goes wrong and why - specifically, whether

\footnotetext{
13 This is the upshot of Murdoch's discussion and may not necessarily be an accurate representation of Zen philosophy, on which she is drawing. It is also a reflection of the Platonic influence on Murdoch's thought: in this passage, the Zen sage is similar to the philosopher in Plato's Republic who, having contemplated the Good, returns to the cave.

14 See Iris Murdoch, Metaphysics as a Guide to Morals (Harmondsworth: Penguin, 1992).

15 Clifton, op. cit., pp. 211-212.

16 Katie Hopkins, "Rescue Boats? I'd Use Gunships to Stop Migrants," The Sun, 17 April 2015.

17 See Simone Weil, Waiting on God, trans. E. Craufurd (Glasgow: Collins, 1978), p. 103.
} 
the moral failure can be understood as a failure of perception - are the questions at hand.

On the non-cognitivist, non-perceptual model (famously advocated, among others, by R.M. Hare ${ }^{18}$, who is one of the main targets of Murdoch's critique), the examples are to be analyzed in terms of perception of non-evaluative facts (presumably spelled out roughly as: "people attempting to illegally migrate to Europe and drowning while doing so;" "an injured man lying by the side of the road;" etc.) plus the application of principles to those facts (e.g. "immigration to one's country must be prevented;" "one is not morally required to stop and help a stranger;" etc.), which yield moral conclusions - according to Hare's theory, in the form of a prescription ("do whatever you can to stop immigration;" "do not stop to help a stranger;" etc.).

If we assume for the sake of argument that what is going on in the cases of Hopkins and of the Levite is morally problematic, Hare's model would explain the flaw as arising either from incorrect principles, or from the incorrect application of principles to the specific situation, resulting in incorrect prescriptions.

\section{Doubts About Moral Perception}

This interpretation would fit with doubts raised in recent discussions of the possibility of actual (direct) moral perception, discussions which at the same time try to do justice to the phenomenology of moral perception. These theories propose a model where the experience of perceiving moral properties is explained by the existence of "moral bridge principles" (Faraci), ${ }^{19}$ or "habitual implicit inferences or transitions in thought" (Väyrynen) ${ }^{20}$ or psychologically immediate judgments made on the basis of how things appear (Harman) ${ }^{21}$. According to this group of views, although we think, say, that we see kindness in a face, it is in fact a thought, formed independently of the perceptual experience, that links with the experience to create this impression. The moral component does not come from the perception itself, but from elsewhere.

Murdoch gives us ways to counter this proposed model in a simpler, more immediate manner, by putting forth a view of perception which is inherently conceptual, thus denying a neat separation between (moral) thoughts on the one hand, and perception on the other. Her alternative begins by urging us to question the idea that all the parties involved have the same perception of the relevant facts, those upon which deliberation is supposed to take place. Whether, for example, Hopkins has actually perceived the refugees and their situation in the same way as someone who takes it as imperative to rescue and help them.

Minimally, we can notice that the situation presents itself to Hopkins differently from the way it does to other observers. The words she uses (notably "cockroaches")

\footnotetext{
18 See R.M. Hare, The Language of Morals (Oxford: Clarendon, 1952).

19 See Faraci, op. cit.

20 See Väyrynen, op. cit.

21 See Harman, op. cit.
} 
as well as statements such as "I don't care" (implying: "there is no moral demand for care"), are emotional-evaluative and suggest that the facts at hand merit a particular response. ${ }^{22}$ Further, Hopkins presents a situation where some aspects are present or foregrounded, and other otherwise-perceivable ones are ignored. What she takes as salient in the refugees' situation is that they are coming to another country uninvited, seeking for a share of the comfort which did not originally legally belong to them. The focus on this aspect, to the exclusion of many others, including the reasons for the journey, what they are fleeing, their fear, etc. contributes to the picture of refugees as threatening, invading nuisances, to whom nothing is owed.

One problem with this picture is that it is limited: the refugees are indeed seeking a share of Europe's safer life and some Europeans are concerned about losing some of their resources because of it; but seeing only this aspect excludes other, highly relevant aspects of the situation, such as the desperation, fear, and danger that are part of the refugees' lot and which could be relieved. Another problem is that, by ignoring or suppressing something which is there (the fear, the danger, the pain) Hopkins's perception, such as I have described it, offers an unrecognizable description of what it is for a person to be in a desperate situation (indeed, she refuses to use words that signal humanity), and at the same time blocks the responses that go naturally with ordinary perceptions of other living beings in distress. Something similar could be said about the biblical story. Removing certain aspects does not only yield an incomplete picture; it yields a false one.

It then seems that a key moral difference between Hopkins and, say, someone who takes the refugees as suffering human beings in need of help and rescue, lies in what Hopkins takes the refugees to be, and in the resulting claim that they make - and the claims they do not make - on her. Hopkins is not saying, for instance, that the refugees are facing a dreadful situation but, unfortunately, helping them would require the use of resources that are due by a certain idea of social contract only to citizens of the U.K. She is saying that refugees are not the kind of beings that elicit concern or compassion.

This interpretation of the given examples does not, as yet, negate the models presented above according to which moral perception is merely apparent. The sceptic about moral perception could accept what has been said so far but point out that what we have just observed only refers to the phenomenology of perception. It is still possible that what presents itself as fact is really an independent perception mediated by judgments, or judgments supervening on perceptions. But Murdoch goes further.

\footnotetext{
${ }^{22}$ It is, of course, highly questionable that cockroaches themselves should be seen as mere nuisances to be killed off without a thought.
} 


\section{Concepts in Perception}

The alternative model presented by Murdoch asks us to observe experience and the concepts we use, as briefly shown above. First, observing moral disagreement leads to perplexity about the possibility of settling even the facts: if perception can be perception of facts, so that one can be said to perceive the facts correctly or not, and if in moral disagreement it is not always possible to agree on the facts, then to understand moral disagreement we need to also look at perception. Second, concept-use is involved in all aspects of moral understanding and discussion in a way that goes very deep. Facts are described by using concepts. But 1) which concepts we use, and 2) how we understand specific concepts, both depend on what we take to be important or relevant, what we have learned, in short, what Murdoch calls "background moral attitudes:"

There would, indeed, scarcely be an objection to saying that there were "moral facts" in the sense of moral interpretations of situations where the moral concept in question determines what the situation is, and if the concept is withdrawn we are not left with the same situation or the same facts. In short, if moral concepts are regarded as deep moral configurations of the world, rather than as lines drawn round separable factual areas, then there will be no facts "behind them" for them to be erroneously defined in terms of. ${ }^{23}$

The first thing we need to do, with Murdoch, is to show that at least some moral concepts are indeed essential to the correct description of a situation, so that, as she writes, without using them the situation is no longer presented as the same situation. If that can be shown to be the case, the second move for perception to count as properly (immediately) moral, will involve showing that concepts, including moral ones, can figure non-inferentially in perception.

The moral concepts that Murdoch has in mind here are clearly what were later called "thick" concepts by Bernard Williams - who, after all, claims to have first heard the "anti-disentanglement" idea, i.e. the idea that some concepts cannot be divided in an evaluative and a descriptive component, from Murdoch herself at Oxford. ${ }^{24}$ Thick concepts are the basic building blocks of ethical discourse for Murdoch, and in The Sovereignty of Good she goes as far as suggesting that "all the moral work" can be done by thick concepts. ${ }^{25}$

For Murdoch, virtually all concepts are both descriptions of the world and expressive of the sensibility of the concept users. Concepts are, at the same time, deeply contextual and world related. She writes: "we learn through attending to contexts,

\footnotetext{
${ }^{23}$ Iris Murdoch, "Vision and Choice in Morality," in P. Conradi (ed.), Existentialists and Mystics: Writings on Philosophy and Literature (Harmondsworth: Penguin, 1999) p. 95, emphasis added.

24 Bernard Williams, Ethics and the Limits of Philosophy (London: Fontana, 1985), p. 218.

25 Murdoch 1970, op. cit., p. 42.
} 
vocabulary develops through close attention to objects, and we can only understand others if we can to some extent share their contexts." 26

\section{Murdoch's Realism}

Murdoch develops her view of concepts as part of her argument supporting moral realism. In arguing for the existence of a moral reality, Murdoch combines the epistemological question of how such reality is accessed with the ontological question about its nature. She combines, in other words, the two senses of moral perception presented above: moral perception considered as the evaluative nature of perception, and as perception of the moral nature of reality. ${ }^{27}$

Moral reality, in Murdoch's thought, drawing significantly on Plato, divides into two kinds: the thin Good or guiding ideal, and thick moral facts and moral properties in the world. The Good is not perceptible due to its nature as an ideal. ${ }^{28} \mathrm{~A}$ limited grasp of the Good is made possible through the perception of moral properties in the world, which act as hints or assembled suggestions of the idea of the Good. This is an exceedingly brief summary of a complex metaphysics, but what is important for our purposes is the appeal to experience: we look at the world, and discover therein valuable things as well as their relationships to each other and to something absolute (the idea of perfection or the Good); at the same time, the discovery of the absolute is the discovery of something which governs the whole of reality, the world and the mind; that indicates that all our acts of cognition are in one way or another structured by an orientation to the Good. ${ }^{29}$

So, on the one hand, cognition and consciousness are inherently evaluative; on the other, value governs not only the mind but also the world - it is not projected, as the anti-realist would have it, by the mind onto the world. Murdoch offers two reasons to think that our evaluating consciousness does not, at the same time, create or project value. First, the mind forms a sense of value through its encounter with the world. The idea of the Good is not a priori, but constantly refined based on what one sees out there. Even the supposedly bridging judgments would not exist without prior perceptions. Second, the claim that the mind perceives reality through moral structures does not need to entail that what is perceived as a moral fact is not part of reality, or that it is a distortion of it. Rather, the mind uses (evaluating) concepts to grasp a reality which is "out there" and separate, but which cannot be grasped independently of those structures. Concepts are like eyes: we see through them, but what we see is not in them. The testing ground of all acts of consciousness, as Murdoch

\footnotetext{
${ }^{26}$ Ibid., p. 32. This line of thinking has been developed by McDowell (Note xxxii), who argues that concept application is something that can only be learned from within a community of concept users, which involves to some extent sharing their concerns, including moral concerns.

27 See Maria Antonaccio, Picturing the Human: The Moral Thought of Iris Murdoch (New York: Oxford University Press, 2000) and David Robjant, “The Earthy Realism of Plato's Metaphysics, or: What Shall We Do with Iris Murdoch?” Philosophical Investigations 35 (2012): 43-67.

28 Murdoch 1999, op. cit., p. 95.

29 This is discussed at length in Chapter 13 of Metaphysics as a Guide to Morals (Note x).
} 
puts it, is the world. So the testing ground of moral perception will be the reality that it takes in. ${ }^{30}$

In this way, Murdoch also combines two important intuitions: the intuition that we construe situations in particular ways, depending on our values, interests and so on; and the intuition that there is a moral truth that is not projected by the mind. Her suggestion is to think of consciousness and perception not as passive instruments affected by an external reality, but rather as tools for interacting with reality to form knowledge: in her own words, not as "mirroring" the world, but as "grasping" it. ${ }^{31}$

\section{Implications for Moral Perception}

This model of perception has important implications. First, by configuring concepts as reaching both to the world and to the mind, it supports the "anti-disentanglement" view of thick concepts, defended by McDowell, according to which some concepts (such as "kind," "cruel," but also "cockroach" as used above) are both descriptive and evaluative at the same time, and without the evaluative aspect the concept would no longer be the same - it would no longer describe the same kind of reality. ${ }^{32}$

Further, Murdoch's model as described above supports the idea that moral concepts are not special kinds of concepts that refer to special kinds of properties or facts, but they are concepts like any other, which in particular contexts and uses take on a more or less explicit moral significance. It follows that we cannot draw neat boundaries around what counts as moral, either in reality or among concepts. $^{33}$ If Murdoch's general picture of the concept-using mind is accepted, the distinction between facts and values begins to blur. ${ }^{34}$ Even in perception, the most basic encounter between mind and world, the world does not present itself to us brutely as unconceptualized sense-data, but via an evaluative concept-using activity. As Murdoch writes: "our deepest imaginings which structure the world in which 'moral judgments' occur are already evaluations. Perception itself is a mode of

\footnotetext{
30 What I have just offered is my interpretation of Murdoch's metaphysics, but it is by no means uncontroversial. In fact, this delicate balance between idealism and realism is probably the main scholarly controversy regarding Murdoch's philosophy. The classic reading is that of Antonaccio (Note xxvii), who attributes to Murdoch a "reflexive realism" where moral reality exists but needs to be apprehended also through self-observation. While Antonaccio is careful to maintain a realist element, her overall position is difficult to combine with Murdoch's constant emphasis on the reality outside of the self. Robjant (Note xxvii) has argued against this position in favour of a more robust realism. The interpretation here presented is more closely aligned to the latter view.

31 Ibid., p. 41.

32 See John McDowell, "Non-Cognitivism and Rule-Following," in Mind, Value and Reality (Cambridge, MA: Harvard University Press, 2001): 198-218.

33 As Cora Diamond (see Note xxxiv) argues, if we follow Murdoch, strictly speaking, value is not really like fact, but prior to fact: the domain of the moral is different from other domains because it is what shapes them. The very distinction between fact and value, therefore, follows this pattern. Given this framework, however, facts and values can converge again, as both are discerned by the evaluating mind.

34 See also Cora Diamond, “We are Perpetually Moralists': Iris Murdoch, Fact and Value," in M. Antonaccio and W. Schweiker (eds.) Iris Murdoch and the Search for Human Goodness (Chicago, IL: University of Chicago Press, 1996), pp. 79-109.
} 
evaluation." 35 This is how, for example, we can say that the mother in law came to "see" the daughter in law differently, or that by conceptualizing the situation in different ways, the Samaritan and the Levite perceived something different in the man lying by the side of the road, or again that Hopkins's perception of what refugees are is not something that can be addressed by arguing about moral principles.

The idea that concepts reach all the way down to perception has been defended more recently from different angles. Here I can only mention three approaches which, while different form Murdoch's, end up forming a similar picture.

The possibility that perception operates through concepts is supported by John McDowell. ${ }^{36} \mathrm{He}$ argues that the possibility of having perception-based beliefs, taken as manifestations of rationality, must be explained by appealing to the rationality of the perception itself. In order to take perceptual experience as a reason in belief formation, the perception has to be rational. And to be rational, one must be able to respond to reasons as such, an ability that involves the deployment of conceptual capacities. To take the perception of a road sign as pointing to the right, conceptual abilities need to be in place.

From a rather different angle, recent developments in the philosophy of perception that build on theories of mental architecture also seem to offer plausible potential grounds for thinking of perception as conceptually rich. These new developments deny Fodor's ${ }^{37}$ standard system, in which input (perceptual) systems are modular, which makes them reliant only on their own resources and unable to use information available in higher cognitive systems, such as concepts. Fodor's view supports the idea that we can only perceive simple or lower-level properties; but recently Carruthers $^{38}$ and others following him ${ }^{39}$ have challenged Fodor's rigid definition of modularity, proposing a cognitive architecture which allows for a progressive degree of cognitive penetration as different modules process and enrich the perceptual raw sense data, which are posted on a central "blackboard" and progressively modified through various experiences. This entails that modules can collaborate with other systems, so that when information is processed as perceptual information, it will be available as rich or higher order information.

This modular cognitive view supports the notion that, from yet a different angle, has recently been discussed under the heading of "cognitive penetration," primarily by Susanna Siegel. ${ }^{40}$ Cognitive penetration is the possibility, in Siegel's definition,

for two subjects (or for one subject in different circumstances) to have visual experiences with different contents while seeing and attending to the same

\footnotetext{
35 Murdoch 1992, op. cit., pp. 314-315.

36 See John McDowell (2006), 'Conceptual Capacities in Perception', in G. Abel (ed.) Kreativität (Hamburg: Felix Meiner Verlag, 2006).

37 See Jerry Fodor, The Modularity of Mind (Cambridge, MA: M.I.T. Press, 1983).

38 See Peter Carruthers, The Architecture of the Mind (Oxford: Clarendon, 2006) and The Opacity of Mind (Oxford: Oxford University Press, 2011).

39 See Jane Suilin Lavelle, "Is a modular cognitive architecture compatible with the direct perception of mental states?" Consciousness and Cognition 36 (2015): 508-518.

40 See Siegel, The Contents of Visual Experience (Oxford University Press, 2010) and "Cognitive Penetrability and Perceptual Justification,” Noûs 46-2 (2012): 201-221
} 
distal stimuli under the same external conditions, as a result of differences in other cognitive (including affective) states. ${ }^{41}$

Such cognitive states include moods, beliefs, knowledge, desires and the possession of particular concepts. While cognitive penetration can distort perception, as in the case, say, of seeing aggressiveness in a refugee's demeanor because of one's existing fears, it can also be epistemically beneficial - for instance, when the mother in law uses her refined understanding of "simplicity" and "love" to modify her perception of D.

The arguments just summarized work together to challenge the assumption that perceptual objects are only of a simple or lower-level nature and support the idea that perception can be of complex or higher-level properties and objects, like a human face or, indeed, a kind gesture. Another important consequence of these types of argument is that perception needs not be mediated by concepts or principles, as proposed by the more skeptical views on moral perception introduced earlier, according to which concepts and principles are bridges between perception and knowledge, but not part of perception. On this Murdoch-inspired view, on the contrary, perception is not mediated, but enriched, by concepts.

The reader will have noticed, however, that the arguments presented in defense of direct moral perception in this section support the idea that we use concepts in perception, but not necessarily moral concepts. Yet, if we allow intellectual, i.e. conceptual capacities to play a role in perception, why should this not be possible with moral concepts as well? To deny this possibility one would need to show that there is a fundamental difference between moral and non-moral concepts insofar as their ability to penetrate perception is concerned. Murdoch has offered reasons, explained above, to doubt this by pointing to the value-ladenness of consciousness. Her model allows us to address two common worries about considering moral concepts in perception on a par with other concepts.

The first worry concerns the idea that moral concepts often require prior knowledge, reflection, refinement, but that is not the case for concepts that allow us to recognise basic objects of perception - say tables and chairs. Therefore, if I "see" something differently after reflection and perhaps discussion, that cannot count as perception proper. Empirical concepts are applied immediately, moral concepts mediately. This assumed distinction is described by Jonathan Dancy as a "fundamental mistake in the philosophy of perception." 42 Dancy uses the example of the car mechanic, who can be described as hearing the malfunctioning of the water pump, rather than as just hearing a particular pattern of sounds and inferring the malfunctioning from it; something similar can be said about listening to a song, or to a conversation, or being able to taste the spiciness of a wine after a wine tasting course. All these are cases where experience, knowledge, familiarity with concepts

\footnotetext{
${ }^{41}$ Ibid., pp. 205-6.

42 Jonathan Dancy, "Moral Perception," Aristotelian Society Supplementary Volume, 84-1 (2010):99117 , p. 111.
} 
and reflection modify perception and do so, importantly, in the direction of greater accuracy.

This is the phenomenon that Murdoch refers to as the "deepening of concepts," particularly important in ethics, but discernible in every experience. Even when it comes to an apparently simple and very immediately applicable concept like "red," Murdoch asks, "why not consider red as an ideal end point, a concept infinitely to be learned?" 43 In some cases, as in the case of the artist trying to find the perfect shade of red for her painting, this may indeed be the case. And what about, indeed, the concept "human being" in the cases of Hopkins, and of the Levite and the priest? I shall return to this below.

The second worry about allowing moral concepts to figure in perception regards the requirement for moral concepts to be intrinsically motivating, which is supposed to set them apart from non-moral concepts. Here again, we can appeal to the intrinsically motivating - or at least reason giving - nature, ceteris paribus, of the application of certain concepts usually regarded as empirical, such as "slippery" or "poisonous." As Chappell has noted, the main point of perception is, in evolutionary terms, precisely that of engendering certain responses. If empirical concepts motivate or give reasons in virtue of their use in human life, so can moral concepts such as "callousness" or "dignity." 44

\section{Against Supervenience}

While the distinctions just mentioned help us to compare two supposedly separate spheres, their point here, as well as Murdoch's overall point, is that no such distinction can be drawn, at least not prior to the particular situation to be assessed. Because of the evaluative nature of consciousness, for Murdoch, any concept is potentially a moral one. (We can think, again, of the concept "red," if used to talk about traffic lights, or about a person's skin...) If concepts are human tools meant to grasp an external reality in human ways, which include evaluation, and if concepts can do so by shaping perception, then it also follows that we no longer need to find links or bridges between the supposedly separate perception of natural properties and that of moral properties.

This goes against not only skepticism about moral perception, but also many of its defenses, which typically appeal to supervenience as the connection between natural and moral properties, while assuming, nonetheless, a fundamental distinction between them. This is the defense of moral perception put forward more generally by Robert Audi $^{45}$ and in the context of Murdoch's philosophy by A.E. Denham (2001). ${ }^{46}$ Denham constructs a convincing case for the possibility of perceiving moral properties, but does so based a distinction between moral properties

\footnotetext{
43 Murdoch 1970, op. cit., p. 29.

44 See Chappell, op. cit.

45 See Audi, op. cit.

46 See Denham, op. cit.
} 
(and other properties, e.g. aesthetic ones) and the "base" properties which are necessary for moral properties to be perceived. Base properties are natural properties. Moral properties depend on them in a relation of supervenience (when a difference in moral properties requires a difference in base properties). Denham calls supervenient moral properties "aspectual" properties: they represent ways of seeing a particular situation. Aspectual or supervenient properties are indeed experienced as direct objects of perception, but upon analysis they can be found to supervene on other properties, which Denham identifies, in the moral case, with "other people's concerns and interests." 47 On this view, moral perception is possible because moral properties are not inferred from non-moral ones but apprehended together. At the same time, moral properties still depend on and differ from non-moral ones. ${ }^{48}$ According to supervenience views, we perceive a face or a smile, but only in virtue of perceiving the lines that make them up: the lines are still primary. In terms of moral perception, supervenience theories would say that the perception of cruelty in a gesture is dependent on the perception of the physical components of the situation, but the two aspects are perceived together.

By Murdoch's lights, however, whereby concepts enter perception in virtue of being "deep moral configurations of the world," 49 there is no reason to suppose that the concept of line is primary in relation to the concept of face, or that people's concerns are primary relative to the moral properties of the situations in which they figure. If moral concepts are human tools to "grasp," in Murdoch's language, the world, then perception reveals a world which is both moral and physical, and inextricably so. Murdoch's attack on the fact/value distinction, starting from concept-use, does not answer but avoids the question: How do we explain why "injustice" or "cruelty" are attributed to "drilling holes in refugees' boats"? In the context in which it is said, in the context in which it is heard, Hopkins's suggestion can be immediately conceptualized in those ways, just as the perception of the physical action is immediately described as "drilling holes...." Murdoch would not see why one needs to be derived from the other. The supervenience model, often presented as the best description of Murdoch's view of moral perception, fails to do justice to her view of perception as conceptual through and through, where the moral difference lies in what we see, and not only what we see things as.

\section{Explaining What Goes Wrong}

One immediate objection to the moral conceptualization just offered of Hopkins's proposal is that not everyone would agree that "unjust" and "cruel" are the correct concepts to use there. Another, related objection, is that there may be many different

\footnotetext{
47 Ibid., p. 613.

48 This model of moral perception can be found, fully fleshed out, in Robert Audi (see Note i) who, similarly to Denham, holds that we perceive moral properties via the perception of their grounds, which are non-moral.

49 Murdoch 1999, op. cit., p. 95.
} 
concepts through which to perceive the situation. The latter is not overly concerning. As long as the concepts and the properties they capture are not among themselves incompatible, many ways of correctly conceptualizing the same reality are possible. On the other hand, disagreement, to which the first objection refers, is often posed as a problem in moral theory, especially in realist and intuitionist accounts of morality; but it may become less worrying if Murdoch can offer us a way to explain how one might perceive things in some ways that are closer to the truth, and others that are less so. If we return one final time to the opening examples, we can now more properly explain what is going wrong there by applying Murdoch's model of moral perception and try to set aside at least some ways of seeing the situations presented.

The discussion of Murdoch's thought highlighted the idea that (moral) concepts are necessary ways of framing the world, making it accessible to the mind. Many concepts, including but not only moral concepts, have a direct link to action, motivation, or reasons for a particular action or stance. They are not, in other words, inert or merely contemplative. This links moral concepts to empirical ones, making them less special than one might think. Because concepts, whilst reaching to the world, are also products of the human mind and of human communities, they are not fixed but can be developed, through thought, analysis and experience, potentially ad infinitum.

Thus moral concepts, like other concepts, are amenable to correction, clarification as well as distortion and avoidance. Moral concepts are refined, clarified and corrected, as Murdoch suggests, by looking both at the world which they are used to capture and at the people who use them. ${ }^{50}$ Murdoch's important insight is that, in doing so, we should focus on the impediments to appropriate concept use - and therefore to clear vision - before focusing on the standards by which we can positively ascertain it.

Both Hopkins, and the priest and Levite, have reasons to distort or suppress the full application of, among others, the concepts of humanity, or fellow living being, to the refugees and the injured man respectively. Such failures are almost always motivated, according to Murdoch, by the presence of the "ego" or self-concern, understood very broadly as the human tendency whereby fear, desire, habit, and other self-protective cognitive states block full recognition of what confronts one. In these examples we can imagine, for instance, nationalistic self-protection in the case of Hopkins, and self-interested desire to arrive at one's destination quickly in the case of the priest and the Levite, or, in both cases, the desire to avoid being confronted with the reality of suffering. In this case, the willful ignorance or denial may be motivated precisely by the awareness that deploying the right concepts in the right way would make a claim on one, coupled with the desire to avoid having to respond to such a claim.

This could be Murdoch's analysis; but even if we reject the suggestion that selfconcern is the root of all distorted vision, it is possible to identify instances of faulty concept application in the cases under consideration. The suffering of other living beings normally presents itself prima facie as undesirable, painful, to be avoided.

${ }^{50}$ Murdoch 1970, op. cit., p. 32. 
It is only through either the suppression of one of these concepts ("living being," "human being," "suffering" ...), or through a process of reasoning leading to the conclusion that other concerns should take priority, that suffering can be ignored, but in very different ways. The latter possibility indeed includes a prior recognition, followed by a (more or less appropriately) motivated rejection. That is not the case in our examples, where what is involved is a framing or vision of the other as not eliciting or meriting any of the responses naturally associated with others' pain. In visual terms, it is a deflection of the gaze away from the full reality of the sufferer. The failures, in the examples at hand, are not just failures of judgment, but failures of fully appreciating the significance of what those human beings, in those contexts, are.

It is possible that there are cases where deflection may be desirable or necessary, for example if being confronted with intense pain is a threat to one's sanity. Our examples do not seem to fall under this category either. What they seem to present is a refusal to observe a reality that is there and to be therefore claimed by that reality in one's responses. They show a lack, as Simone Weil put it in relation to the Samaritan, of "the interval of hesitation" which signals that the other has been recognizes as other, fellow subject in a life but also independent of oneself and of one's desires for things to be a certain way. ${ }^{51}$

The application and deepening of concepts requires particular faculties and attitudes on the part of the subject, including what Murdoch and Weil called "attention:" the real moral work, in this framework, involves the removal of self-created impediments, as well as the active reaching out to reality in order to refine one's concepts and be maximally receptive to the reality that shapes them.

\section{Conclusion}

I have presented an alternative model of the way the mind interacts with the world, drawn from Murdoch's philosophy, to support the possibility of moral perception. Concept-application, on this view, is an integral part of the process of perception, and morality is seen as an essential aspect of concept-making. Accepting this picture has consequences, first and foremost, for moral knowledge, because it explains how moral knowledge can be achieved by evening out the field, so to speak, and applying the same model to the knowledge of both moral properties and what we consider to be non-moral properties. Claims to moral knowledge are then analyzed by looking at the process of perception and the perceiving agent, including the concepts used, rather than by attempting to settle empirical and moral properties independently of the participants.

This model takes moral disagreement seriously, but questions the assumption that disagreement must rest on the moral element alone, indeed questioning the possibility of separating the moral from the non-moral. Disagreement on this view is addressed through analysis of the individual perceivers, the concepts used, both in

\footnotetext{
51 See Simone Weil, The Iliad or the Poem of Force, trans. M. McCarthy (Wallingford, PA: Pendle Hill, 1956), p. 33.
} 
their public and private elements, and the whole world-view that shapes both the person and her concepts. This explains why, in some cases, moral disagreement can be radical, because based on irreconcilable perceptions of reality, which are not settled by any appeal to principles. This is bad news for the hope that moral disagreement can always be resolved, but Murdoch's view does not leave us powerless in the face of it, even if the path to resolution is longer and more complex than the analysis of the consistency and rationality of moral principles alone.

A more positive consequence for moral disagreement also ensues: as we saw, if moral concepts shape the facts one perceives, it is also possible for there to be several compatible but different perceptions in the same contexts, without it being a cause for worry. Reality can be captured and framed in different ways. At the same time, there will be perceptions that are not fitting. As Wittgenstein put it, "Say what you choose, so long as it does not prevent you from seeing the facts. (And when you see them there is a good deal that you will not say.)"

In conclusion, Murdoch's model seems to be one of the simplest ways of capturing ordinary experience of the moral life without falling into contradictions. While I have attempted to present Murdoch's view of moral perception as an alternative to a more widely accepted one, it is only possible to draw this contrast tentatively: it is part of Murdoch's thought that work on moral concepts can only be done internally to a world where moral concerns are felt as real; so that perhaps those whose experience is truly of a world where the only real and perceptible objects are those of raw sense data discovered by empirical science, if they are there, may not be encountered quite on the same terms.

Open Access This article is distributed under the terms of the Creative Commons Attribution 4.0 International License (http://creativecommons.org/licenses/by/4.0/), which permits unrestricted use, distribution, and reproduction in any medium, provided you give appropriate credit to the original author(s) and the source, provide a link to the Creative Commons license, and indicate if changes were made.

Publisher's Note Springer Nature remains neutral with regard to jurisdictional claims in published maps and institutional affiliations.

\footnotetext{
${ }^{52}$ See Ludwig Wittgenstein, Philosophical Investigations, fourth edition, trans. G.E.M. Anscombe, P.M.S. Hacker and J. Schulte (Oxford: Wiley-Blackwell, 2009), para. 79.
} 